\title{
Facet Median Branch Radiofrequency Thermocoagulation Treatment at Different Temperatures and Durations in Patients with Lumbar Facet Syndrome: A Randomized Controlled Double-Blind Study
}

\author{
Esra ERTILAV ${ }^{1}$, Osman Nuri AYDIN¹, K. Varlik EREL ${ }^{2}$ \\ ${ }^{1}$ Adnan Menderes University, School of Medicine, Department of Neurology, Division of Algology, Aydin, Turkey \\ ${ }^{2}$ Adnan Menderes University, School of Medicine, Department of Anesthesiology, Aydin, Turkey \\ Corresponding author: K. VARLIK EREL varlik.erel@gmail.com
}

\section{ABSTRACT}

AIM: To evaluate the effect of various temperatures and durations of radiofrequency thermocoagulation (RFT) for the treatment of low back pain that is caused by facet joints.

MATERIAL and METHODS: This is a randomized controlled, double-blind study. Patients diagnosed with facet syndrome were randomly divided into three groups. RFT was applied to the medial branches, which received senses from the facet joint $90^{\circ} \mathrm{C}$ 50 seconds in 31 patients, $85^{\circ} \mathrm{C} 60$ seconds in 32 patients, $70^{\circ} \mathrm{C} 90$ seconds in 33 patients at constant current and impedance values. Numeric Rating Scale (NRS) scores before and after the treatment (1 and 6 months), the need for additional analgesics after treatment, and opioid dose changes were recorded.

RESULTS: The demographic data of the groups were similar. NRS scores in all three groups were significantly lower at 1 and 6 months $(p<0.001, p<0.001, p<0.001$, respectively). At the first and sixth months, there was no significant difference between the groups in patients who experienced a $50 \%$ reduction in pain intensity $(p=0.1, p=0.7$, respectively). Patients who had back surgery had a significantly lower rate of pain regression $(p=0.001)$.

CONCLUSION: In patients with lumbar facet syndrome, RFT application in every 3 degrees and seconds is effective because it generates equal energy, and there was no significant difference in pain relief between the groups.

KEYWORDS: Facet syndrome, Radiofrequency thermocoagulation, Low back pain, Medial branch, Facet denervation, Neurotomy

\section{INTRODUCTION}

0 eventy-eighty percent of the society experience low back pain at least once at some point in their life (1). Low back pain can occur due to trauma, infections, and neoplastic causes, mainly mechanical and rheumatologic causes. $15-40 \%$ of low back pain develops due to trauma or degeneration of facet joints (4). In the facet joint, which is a synovial joint, degeneration and osteoarthritis increase significantly with increasing age. Initially, synovial hypertrophy occurs as a result of synovial cell proliferation. In the articular cartilage, osteophytes develop in the adhesion areas of subchondral bone sclerosis, ligamentum flavum, and joint capsule. Degenerative changes of articular facets cause local inflammation and pain. In disc degeneration, the disc distance becomes narrower, the load on the facet joints increases, and clinical symptoms appear. Additionally, axle disorders caused by spondylolisthesis impair the harmony of the facet joints. Collapse and degeneration between the facet joints cause irritation of the nerves innervating the joint. 
Low back pain without radicular spread and pain that does not extend under the knee is characteristic of facet joint pain. Standing, lumbar extension, lateral flexion, and rotation to the problematic side exacerbate the pain. Rotational movements are especially painful in facet joint pathologies. Pain is reduced with sitting and lumbar flexion.

Facet joint syndrome pain is treated with medical treatment, physical therapy, invasive percutaneous procedures, and surgical treatment. Treatment includes using analgesic, myorelaxant, nonsteroidal anti-inflammatory drugs, and antidepressant medications, and bed rest for several days in the acute period. Opioids can be used in resistant pain. In addition, facet joint injections and medial branch blocks reduce the pain of the patient. In cases where medical methods are not successful, and patients benefit from diagnostic blocks, facet medial nerve denervation is applied by RFT.

While RFT has been used for facet syndrome since 1970, Shealy first described the medial branch lesion in the treatment of pain caused by facet joints in the lumbar and cervical region in 1975 (14). The radiofrequency process is an effective and safe method with few complications $(7,9,10,13,17,18)$. Reported success rates are $40-65 \%$ for medial branches $(16,17)$. The effectiveness of the method has been proven by doubleblind studies $(9,13,17)$. Temperature and voltage-controlled groups were compared in the study, different techniques of facet median branch RFT were applied; It was concluded that creating a temperature-controlled lesion is more controlled (2).

There is a retrospective study where RFT is applied to the medial branch with different temperatures in the literature (6). However, we could not reach any randomized controlled study in which RFT was applied to the medial branch at different temperatures, different durations, and equivalent heat energy calculations were made. In this study, we aimed to evaluate the pain relief results of patients with three different temperatures and durations; RFT lesions provided by keeping constant current and impedance values.

\section{MATERIAL and METHODS}

\section{Study Design}

This was a randomized controlled, double-blind study. After institutional approval (2017/1064 Ethics Committee), the study was carried out between April 2017 and June 2019. Consent forms were obtained from all patients and volunteers who participate in the study.

\section{Inclusion/Exclusion Criteria}

Ninety-six patients who were evaluated by history and examination, excluding other causes of low back pain with X-ray and MRI and diagnosed with facet syndrome, were included in the study. The informed, voluntary consent form was obtained from all patients. Patients who had low back and hip pain for at least six months and had no neurological deficit and at least $50 \%$ reduction in pain after nerve block to the medial branches of the posterior primary ramus were included in the study. Patients with signs of coagulopathy and infection were excluded from the study.

\section{Randomization}

Patients were randomized in a $1: 1: 1$ ratio by computergenerated random sequence to apply median branch RFT for $90^{\circ} \mathrm{C}$ for 50 seconds in Group I, $85^{\circ} \mathrm{C}$ for 60 seconds in Group II, and $70^{\circ} \mathrm{C}$ for 90 seconds Group III.

\section{Blinding}

All patients were administered by a single algologist. The duration and degrees of the application were conducted by the anesthesia technician. The algologist was blind to the application duration and degrees. Pre-application evaluations and post-application scores were made to all patients by another physician. The evaluating physician was blinded to patients of all groups in the outpatient clinic.

\section{Study Procedure}

Application to all patients was made by a single algologist. RFT; with fluoroscopy, in the prone position, the patient's vascular access was performed. ECG, pulse oxymetry, and pulse monitoring were performed by providing sterile conditions with $0.05 \mathrm{mg} / \mathrm{kg}$ midazolam and $1 \mu \mathrm{cg} / \mathrm{kg}$ fentanyl under mild sedation. After providing skin and subcutaneous anesthesia with $2 \%$ lidocaine, a $10 \mathrm{~cm}$ long cannula with a $10 \mathrm{~mm}$ active tip was used. The target point for the neurotomy of the medial branch of the posterior ramus of the L2-L5 spinal nerves was determined as the groove consisting of the combination of the transverse process and the superior articular process.

RFT was applied with anterior-posterior position with a distal approach as parallel to the median nerve with $\mathrm{C}$-arm for medial branch neurotomy of L4-5 and L5-S1 facets joints (Figure 1AC). Then, RFT was applied by the tunnel image was obtained at 20-25 degrees lateral oblique and 10-15 degrees caudal position after the anterior, posterior and lateral images were confirmed with C-arm for medial branch neurotomy of the L2-3 and L3-4 facet joints (Figure 2A-C). Sensory stimulus 50 $\mathrm{Hz}$; 1v, motor stimulus $2 \mathrm{~Hz}$; after $2 \mathrm{v}$ test, the local anesthetic injection was performed with $2 \mathrm{cc}$ bupivacaine for each level. The lesion was performed with a radiofrequency generator (Neurotherm NT1100 / 13001-12) for 90, 85, 70 degrees $\left({ }^{\circ} \mathrm{C}\right)$ for $50,60,90$ seconds, respectively. NRS and functional status of patients before and after the procedure were evaluated at first and at the sixth months. Analgesics, opioid doses, previous spinal surgery history, accompanying additional conditions (sacroiliac dysfunction, disc herniation, narrow spinal canal) were recorded.

Theoretically, in a homogeneous tissue, energy (Q) transmitted to the tissue during RF application and causing heat generation is calculated as follows: $\mathrm{Q}=\mathrm{Pxt}(\mathrm{P}$; energy and $\mathrm{t}$ in watts, transmitted to the tissue in 1 second; It is the time in seconds).

In a formula where I (amp) is the electric current in amperes, and $\mathrm{V}$ (volt) is the voltage difference in volts, the equation can be rearranged as follows: $P=|x V, Q=| x V x t$

In another equation, the role of the impedance [R (Ohm)] is observed: $V=I x R$

As a result; $\mathrm{Q}=\mathrm{I}^{2} \times \mathrm{R} \times \mathrm{t}$ or $\mathrm{Q}=\mathrm{V}^{2} \times \mathrm{t} / \mathrm{R}$ equations are obtained. 


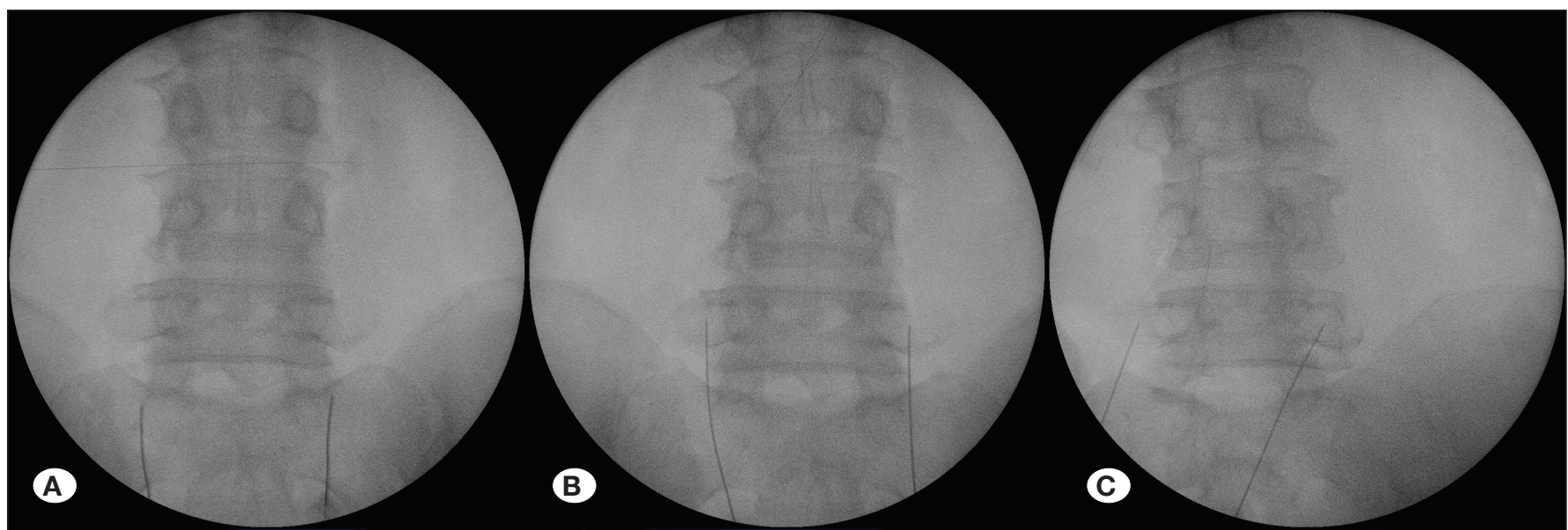

Figure 1: A) Fluoroscopically posterior-anterior (PA) view of cannulas placed paralel to L5-S1 facet median branches with distal approach B) Fluoroscopically PA view of cannulas placed paralel to L4-5 facet median branches with distal approach. C) Fluoroscopically oblique view of cannulas placed paralel to L4-5 facet median branches with distal approach.

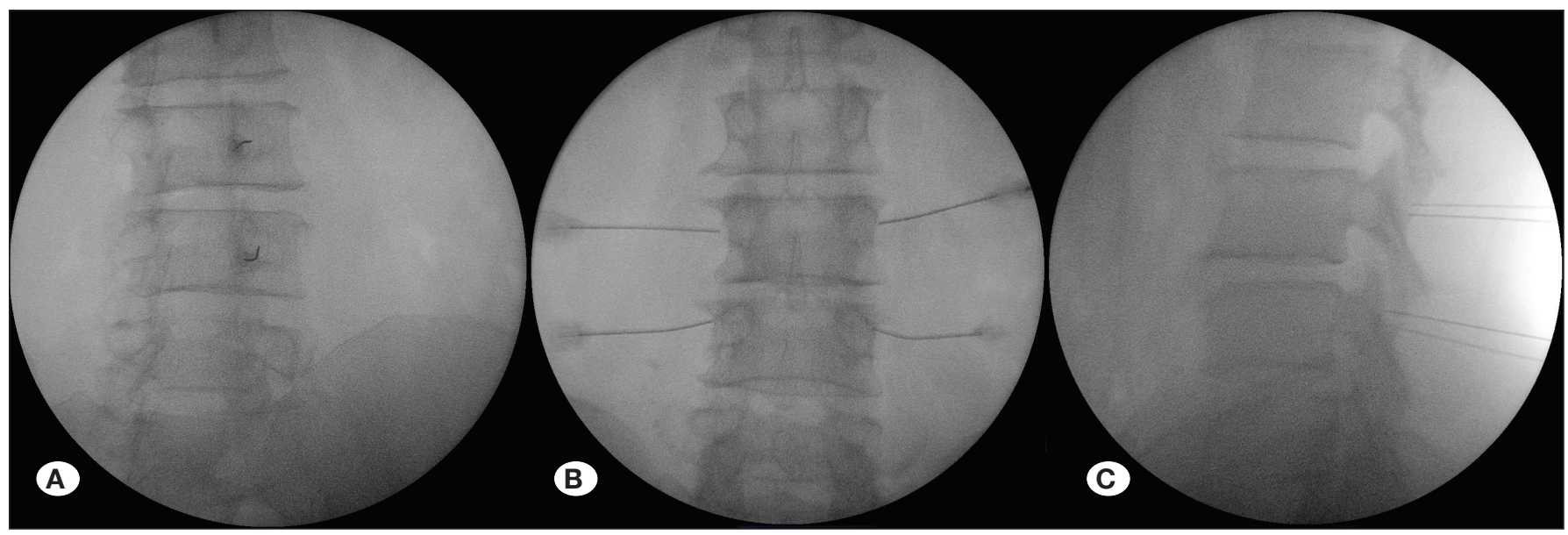

Figure 2: A) Fluoroscopically oblique view of the cannulas placed perpendicular to the L3-4 and L2-3 facet median branches by tunnel vision approach. B) Fluoroscopically PA view of the cannulas placed perpendicular to the L3-4 and L2-3 facet median branches with the tunnel vision approach. C) Fluoroscopically lateral oblique view of the cannulas placed perpendicular to the L3-4 and L2-3 facet median branches using a tunnel vision approach.

These formulas are effective in determining the size of the lesion; it explains how it is affected by voltage, current, impedance and application duration.

During applications, impedance monitoring was also applied to check the integrity and short-circuit formation of the circuit and ensure the electrode's correct placement. While the impedance of extradural structures varies between 300 ohms and 600 ohms, the impedance of the medulla spinalis was above 1000 ohms, the impedance of the posterior ramus was 600-700 ohms, and the intervertebral disc was below 200 ohms. In the study, by keeping the current and impedance constant in heat energy equivalent, the time values for the same lesion size at different temperatures were calculated using these formulas.

\section{Statistical Analysis}

The results of a previous similar study (6) were used for the calculation of the sample size. Twenty-eight patients were needed in each group to detect a significant difference between VAS scores of groups at a study power of $95 \%$ and a error of 0.05 in the power analysis of the study (6).

Demographic and score parameter data were tabulated by descriptive analyses and frequencies. The chi-square test was used by cross-tabulation in statistical analysis. Kruskal-Wallis ANOVA test and pairwise interactions were used to determine the score comparisons in groups. The statistical significance set as $p<0.05$, and analysis was performed by the SPSS Statistics 22.0 program.

\section{RESULTS}

The mean age in 96 patients (70 females, 26 males) was $62.3 \pm$ 2.01 (min:34, max:84), and demographic characteristics were given in the table (Table I). There was no significant difference 
between groups in terms of age and BMI $(p=0.3$ and $p=0.5)$. The number of women was significantly higher in all three groups $(p=0.025)$.

While 21 of 49 patients with secondary etiology of back pain had $<50 \%$ pain relief, 28 patients had pain relief $\geq 50 \%(p=0.4)$. Two of the 18 patients with previous back surgery had $\geq 50 \%$ in pain relief $(p=0.001)$.

While $45 \%$ of patients with $\mathrm{BMl} \geq 30$ had $\geq 50 \%$ in pain relief, $60 \%$ of patients with $\mathrm{BMl}<30$ had $\geq 50 \%$ in pain relief $(p=0,33$ and $p=0,63$, respectively). Pain relief $\geq 50 \%$ was present in $83 \%$ of the patients who had analgesic cutting. In $95 \%$ of the patients whose opioid dose was reduced, there was $\geq 50 \%$ in pain relief. There was a significant difference between pain regression and analgesic cutting and opioid dose reduction ( $p=0.002$ and 0.001 , respectively)

Pre-procedure (NRS 0), post-procedure 1 month (NRS 1) and 6 months (NRS 6) scores were similar in all three groups $(p=$ $0.6,0.4,0.9$, respectively) (Table II). NRS scores in all three groups were significantly lower at first and sixth months when evaluated in the first and sixth months follow-up before and after the procedure $(p=0.00, p=0.00, p=0.00$, respectively).

There was no statistically significant difference between the groups separated according to three different temperature values in patients with $\geq 50 \%$ pain relief with facet median branch RFT in the first and sixth months $(p=0.1$ and $p=0.7$, respectively) (Table III).

In 6 months, there was opioid dose reduction in 21 patients and analgesic cut in 18 patients, but there was no significance between the groups ( $p=0.2$ and $p=0.1$, respectively).

Eighteen patients with previous surgery were in similar rates in three groups $(p=0.8)$. Moreover, there was no significant difference in all three groups for 49 patients with secondary etiology, such as lumbar disc herniation, spondylosis, spinal stenosis, spondylolisthesis, sacroiliac dysfunction $(p=0.1)$.

\section{DISCUSSION}

Facet joint median branch RFT is an effective method in the treatment of chronic pain, which can be safely applied in patients with facet syndrome. Its effectiveness has been proven in randomized controlled studies. Many studies have been conducted investigating the factors that change RFT efficiency in facet syndrome. The effectiveness of this technique, which is widely used in facet arthropathy, is dependent on a number of patient and technique-related factors.

We did not find a significant difference in the results of $\geq 50 \%$ in pain relief in the first and sixth months, comparing all groups in this study. In a similar retrospective study of Costandi et al. (6), in which the relationship between temperature and functional recovery was evaluated, it was concluded that creating a temperature lesion at $90^{\circ} \mathrm{C}$ had better results on functional recovery compared to $80^{\circ} \mathrm{C}$. However, the temperature was the only variable in this study, and the duration and active electrode diameter were kept constant, and the results were obtained better at high-temperature values. Our results indicate that there was no significant difference among the three groups. We propose that the conflicting results in Costandi et al. (6) could be due to the difference in heat energy levels, which are equal in our study but unequal in their study.

In a study evaluating the relationship of patient-related factors with RFT success, RFT failure was found to be associated with factors such as duration of pain, previous lumbar surgery, and axial loading (3). In our study, the facet median branch

Table I: Demographic Characteristics of the Groups

\begin{tabular}{llcccc}
\hline & & Group I & Group II & Group III & p \\
\hline Age (years) & & $63.3 \pm 1.7$ & $57.1 \pm 2.4$ & $65.7 \pm 1.9$ & 0.3 \\
\hline \multirow{2}{*}{ Gender } & Male & 3 & 12 & 11 & \multirow{2}{*}{0.02} \\
\cline { 2 - 5 } & Female & 28 & 19 & 23 & \\
\hline BMI $\left(\mathrm{kg} / \mathrm{m}^{2}\right)$ & $27.6 \pm 0.8$ & $28.4 \pm 0.7$ & $30.7 \pm 0.7$ & 0.5 \\
\hline Previous back surgery & $16.1 \%$ & $19.4 \%$ & $20.6 \%$ & 0.8 \\
\hline Secondary etiology of low back pain & $61.3 \%$ & $54.8 \%$ & $38.2 \%$ & 0.1 \\
\hline
\end{tabular}

Table II: Comparison of the Groups' Mean NRS Scores in the Pre-Procedure, Post-Procedure 1 and 6 Months

\begin{tabular}{lcccc}
\hline & Group I & Group II & Group III & p \\
\hline NRS (0) & 8.2 & 8 & 8.1 & 0.6 \\
\hline NRS (1) & 4 & 4.5 & 4.2 & 0.4 \\
\hline NRS (6) & 4.4 & 5.1 & 4.7 & 0.9 \\
\hline
\end{tabular}

NRS: Numeric rating scale. 
Table III: Comparison of the Groups' Pain Relief Rates in the $1^{\text {st }}$ and $6^{\text {th }}$ Months

\begin{tabular}{|c|c|c|c|c|}
\hline & $\begin{array}{c}\text { Group I } \\
\text { (n) }\end{array}$ & $\begin{array}{c}\text { Group II } \\
\text { (n) }\end{array}$ & $\begin{array}{c}\text { Group III } \\
\text { (n) }\end{array}$ & $\mathbf{p}$ \\
\hline \multicolumn{5}{|c|}{ Pain relief in the $1^{\text {st }}$ month } \\
\hline$\geq 50 \%$ & 22 & 16 & 23 & \multirow{2}{*}{0.1} \\
\hline$<50 \%$ & 9 & 16 & 10 & \\
\hline & $\begin{array}{c}\text { Group I } \\
\text { (n) }\end{array}$ & $\begin{array}{c}\text { Group II } \\
\text { (n) }\end{array}$ & $\begin{array}{c}\text { Group III } \\
\text { (n) }\end{array}$ & $\mathbf{p}$ \\
\hline$\geq 50 \%$ & 19 & 16 & 20 & \multirow{2}{*}{0.7} \\
\hline$<50 \%$ & 12 & 16 & 13 & \\
\hline
\end{tabular}

RFT efficacy results were significantly worse in patients with previous back surgery. These data are in the same direction as a previous study. After the previous surgery, the load on the facet joints increases due to the deterioration of spinal stabilization, which increases the existing facet joint degeneration.

Again, in a study examining the relationship between BMI, gender, active sports, and RFT treatment results, the results were better in patients with $\mathrm{BMl}<30$ and in the group engaged in active sports, but again, gender did not differ significantly (15). In our study, there was no significant difference between $\mathrm{BMI}$ and pain relief.

Comparing the groups with and without concomitant secondary low back pain etiology, we found no significant difference. This situation can be explained by a good clinical evaluation, including patients with additional lumbar pathology and clinically prominent facet syndrome. Additional pathologies of patients with radiologically or subclinical symptoms were ineffective on our pain regression results.

In studies on the relationship between procedure technique and success, it has been shown that electrode placement with the distal approach is associated with better results (12). Considering the course of the median branch that innervates the facet joints, more effective results can be obtained as the lesion is formed parallel to the nerve with the distal approach. We applied the distal approach at the inferior four levels and the classical tunnel approach to the upper four levels in our study.

In studies with proven median branch RFT efficacy, success rates were observed to be $50 \%$ pain reduction in at least $50 \%$ of patients (5). In our study, the rate of patients with regression of at least $50 \%$ in pain supports the literature with $57.2 \%$. While the relationship between efficacy and gender was not demonstrated in those studies, in our study, the female gender was dominant, but there was no significant difference in terms of efficacy in both genders.

Significantly, the majority (83\% and $95 \%$ ) of the patients whom analgesic and opioid dose reduction were applied at the sixth month experienced decreased pain. RFT therapy is an effective method in long-term follow-up in patients with facet syndrome. The effectiveness of the interventional procedure was demonstrated by reducing analgesic and opioid therapy in the long-term follow-up in the study.

The destruction of tissue targeted by ablation in RFT treatment depends on temperature. The size of the lesion formed varies according to the temperature and time. While neuronal destruction does not occur below 45 degrees, RFT current is not efficient since gas formation will occur above 105 degrees (11). While high-temperature values are generally not recommended due to neural damage, neuritis, deafferentation pain, and necrosis of paravertebral muscles, low temperatures may not create an effective lesion. In our study, we evaluated RFT efficiency to generate equal heat energy as a basic principle at three different temperatures at different times. As equal clinical results at all three temperatures were obtained, the choice of 50 seconds at $90^{\circ} \mathrm{C}$ for RFT can save time at the procedure. Although creating lesions at $70^{\circ} \mathrm{C}$ for 90 seconds can be applied relatively more safely, the 8-level facet joint median branch ablative lesion that we routinely apply requires a longer time in practice. In our routine clinical practice, we apply facet joint median branch RFT for 60 seconds at $85^{\circ} \mathrm{C}$. In this study, no additional complications were observed in the 90-degree group compared to the other groups. It may be thought that creating RFT lesions at high temperatures may cause subclinical denervation and atrophy in the multifidus muscles. Dreyfuss et al. (8) detected radiological atrophy was after RFT, but they specified that it did not cause pain in 12-months follow-up and did not require additional treatment. The results of our study showed that other temperatures might also be effective.

The most important limitation of our study is the lack of longterm follow-up. The effectiveness of RFT treatment may give different results regarding whether there is a significant difference between groups in long-term follow-up. In addition, the lower temperature degree and the shorter duration group of RFT can be considered as a limitation of our study. In this study, we did not have this group because we calculated the temperature degree and duration according to the equal energy principle. 


\section{CONCLUSION}

Facet median branch RFT treatment is an effective method in patients with chronic pain with facet syndrome. In this study, we obtained equal efficacy when we performed neuroablation by keeping the time variable with different temperature values and creating equal heat energy. By showing that different temperatures can be used safely in the treatment of median branch RFT in facet syndrome, we think that our study will present an alternative to the literature in RFT application technique.

\section{ACKNOWLEDGEMENT}

We wish to thank all authors for their contributions.

\section{REFERENCES}

1. Arinez-Barahona E, Navarro-Olvera JL, Vega-Sosa A, Esqueda-Liquidano MA, Munoz-Cobos A, Laredo-Gómez $J$, Rivera-Arroyo AD, Méndez-Viveros A: Radiofrequency thermocoagulation in chronic low back pain from the facet joints: Literature review. Rev Méd Hosp Gen (Méx) 80(3):185190, 2017

2. Buijs EJ, van Wijk RM, Geurts JW, Weeseman RR, Stolker RJ, Groen, GG: Radiofrequency lumbar facet denervation: A comparative study of the reproducibility of lesion size after 2 current radiofrequency techniques. Reg Anesth Pain Med 29(5):400-407, 2004

3. Cohen SP, Hurley RW, Christo PJ, Winkley J, Mohiuddin MM, Stojanovic MP: Clinical predictors of success and failure for lumbar facet radiofrequency denervation. Clin J Pain 23:4552, 2007

4. Cohen SP, Raja SN: Pathogenesis, diagnosis, and treatment of lumbar zygapophysial (facet) joint pain. Anesthesiology 106(3):591-614, 2007

5. Cohen SP, Strassels SA, Kurihara C, Lesnick IK, Hanling SR, Griffith SR, Buckenmaier 3rd CC, Nguyen C: Does sensory stimulation threshold affect lumbar facet radiofrequency denervation outcomes? A prospective clinical correlational study. Anesth Analg 113:1233-1241, 2011

6. Costandi S, Garcia-Jacques M, Dews T, Kot M, Wong K, Azer G, Atalla J, Looka M, Nasr E, Mekhail N: Optimal temperature for radiofrequency ablation of lumbar medial branches for treatment of facet-mediated back pain. Pain Pract 16(8):961968, 2016

7. Dreyfuss P, Halbrook B, Pauza K, Joshi A, McLarty J, Bogduk $\mathrm{N}$ : Efficacy and validity of radiofrequency neurotomy for chronic lumbar zygapophysial joint pain. Spine 25(10):12701277,2000
8. Dreyfuss P, Stout A, Aprill C, Pollei S, Johnson B, Bogduk $\mathrm{N}$ : The significance of multifidus atrophy after successful radiofrequency neurotomy for low back pain. Spine J 1(8):719722, 2009

9. Lakemeier S, Lind M, Schultz W, Fuchs-Winkelmann S, Timmesfeld N, Foelsch CA, Peterlein CD: Comparison of intraarticular lumbar facet joint steroid injections and lumbar facet joint radiofrequency denervation in the treatment of low back pain: A randomized, controlled, double-blind trial. Anesth Analg 117(1): 228-235, 2013

10. Lee $\mathrm{CH}$, Chung $\mathrm{CK}$, Kim $\mathrm{CH}$ : The efficacy of conventional radiofrequency denervation in patients with chronic low back pain originating from the facet joints: A meta-analysis of randomized controlled trials. Spine J 17(11):1770-1780, 2017

11. Manchikanti L, Kaye AD, Boswell MV, Bakshi S, Gharibo CG, Grami V, Grider JS, Gupta S, Jha SS, Mann DP, Nampiaparampil DE, Sharma ML, Shroyer LN, Singh V, Soin A, Vallejo R, Wargo BW, Hirsch JA: A systematic review and best evidence synthesis of effectiveness of therapeutic facet joint interventions in managing chronic spinal pain. Pain Physician 18(4): E535-582, 2015

12. Moon JY, Lee PB, Kim YC, Choi SP, Sim WS: An alternative distal approach for the lumbar medial branch radiofrequency denervation: A prospective randomized comparative study. Anesth Analg 116(5):1133-1140, 2013

13. Nath S, Nath CA, Pettersson K: Percutaneous lumbar zygapophysial (facet) joint neurotomy using radiofrequency current, in the management of chronic low back pain: A randomized double-blind trial. Spine 33(12):1291-1297, 2008

14. Shealy CN: Percutaneus radiofrequency denervation of the lumbar facets. J Neurosurgery 43:448-451, 1975

15. Stelzer W, Stelzer V, Stelzer D, Braune M, Duller C: Influence of BMI, gender, and sports on pain decrease and medication usage after facet-medial branch neurotomy or SI joint lateral branch cooled RF-neurotomy in case of low back pain: Original research in the Austrian population. J Pain Res 10:183, 2017

16. Tzaan WC, Tasker RR: Percutaneous radiofrequency facet rhizotomy-experience with 118 procedures and reapprasial of its value. Can J Neurol Sci 27:125-130, 2000

17. van Kleef M, Barendse GA, Kessels A, Voets HM, Weber WE, de Lange S: Randomized trial of radiofrequency lumbar facet denervation for chronic low back pain. Spine 24(18):1937, 1999

18. Zhou Q, Zhou F, Wang L, Liu K: An investigation on the effect of improved X-rays-guided radiofrequency thermocoagulation denervation on lumbar facet joint syndrome. Clin Neurol Neurosurg 148:115-120, 2016 